\title{
Inferindo personalidade por meio de histórias
}

\author{
Guilherme Gomes Cardoso ${ }^{1}$ \\ Maria Augusta Silveira Netto Nunes ${ }^{1}$
}

\begin{abstract}
Resumo: Recentemente aspectos sutis do ser humano começaram a ser estudados e utilizados por computadores, um desses é a personalidade. Existem vários estudos que analisam como estruturála e extraí-la computacionalmente. No entanto, um dos gargalos no seu estado da arte atual é a forma não sutil para inferir personalidade do usuário. Este trabalho tem como objetivo mostrar o relato de uma experiência que demonstra os passos iniciais e os resultados parciais de uma pesquisa em andamento sobre um método alternativo e mais sutil para inferir a personalidade do usuário. Os resultados apresentam o uso de histórias como uma abordagem promissora, entretanto demanda novos testes baseados em metodologias estatisticamente mais consistentes.
\end{abstract}

Palavras-chave: Mineração de personalidade. Personalidade. Teste de personalidade baseado em histórias.

\begin{abstract}
Recently subtle aspects of humans began to be studied and used by computers, one of them it's the personality. There are several studies that analyse how to structure it and extract it computationally. However one of the bottlenecks in its actual state of art is how to infer personality softly from user. This work aims to show the partial results of an on going research about an alternative method towards to infer the user's personality. Our results are promising. However, new experiments should be done using more significant statistical methods.
\end{abstract}

Keywords: Personality mining. Personality. Story-based. Personality test.

\section{Introdução}

A personalidade tem sido estudada por diferentes teorias, as quais não consensuam nem em seus conceitos nem em sua forma de representação [1]. Uma teoria interessante e implementável em computadores é a teoria de Traços. Um modelo bastante difundido na teoria de Traços é o modelo de personalidade Big Five [2], o qual estrutura a personalidade em cinco fatores: agradabilidade, estabilidade emocional, abertura a experiências, consciência e extroversão. Entretanto, existem pesquisadores que subcategorizam cada fator em subfatores chamados de facetas. Por exemplo, Johnson [3] e John e Strivastava [2] determinam seis facetas (subfatores) para cada fator Big Five, de modo que todo o conjunto (cinco fatores com seis facetas cada) representa a personalidade de um indivíduo. Essa representação enriquece a representação da personalidade humana considerando trinta traços/características que expressem tendências ao comportamento de um cliente/usuário.

Modelos de personalidade são úteis para tomada de decisão computacional, porém, um dos atuais problemas está em como extrai-lo/inferi-lo de um usuário/cliente de forma intencional por meio de testes de mensuração de personalidade, como, por exemplo, o consolidado NEO-IPIP 300 [4]. O maior problema do NEO-IPIP 300 é sua extensão, constituído de trezentas questões, o que pode levar alguns usuários a desistirem de completar o teste, inviabilizando, assim, a inferência de sua personalidade. Johnson [3] criou uma versão alternativa e menor do NEO-IPIP 300, contendo 120 questões, diminuindo em mais de $50 \%$ do tamanho original. Em seus estudos, Johnson [5] mostra que a versão menor do teste é, também, consistente e confiável, porém em

\footnotetext{
${ }^{1}$ DCOMP/PROCC, UFS, Cidade Universitária- Rosa Elze - São Cristóvão-SE - Brasil

\{gcardoso18; gutanunes@gmail.com\}
}

http://dx.doi.org/10.5335/rbca. 2014.3782

Revista Brasileira de Computação Aplicada (ISSN 2176-6649), Passo Fundo, v. 6, n. 2, p. 113-122, out. 2014113 
menor escala se comparado ao NEO-IPIP 300. Apesar de ser confiável para inferir a personalidade, o NEO-IPIP 120, ainda é oneroso ao usuário, fato que cria uma lacuna interessante para o experimento apresentado neste artigo.

Inferir a personalidade do usuário pode ser útil para tomada de decisão computacional, visando diversas finalidades, tais como, por exemplo: personalização de interfaces; recomendação produtos, que sejam mais próximos às preferências do cliente; recomendação de novas comunidades virtuais com base em afinidades dos participantes, entre outros [6].

Objetivando criar um método computacional alternativo para inferir a personalidade humana, esse artigo propõe uma técnica de se mensurar a personalidade por meio de estórias (enredos) aplicadas ao usuário. A hipótese criada é que há uma correlação entre os testes NEO-IPIP baseados em questionários e o teste baseado em estórias/enredos proposto por esta pesquisa.

$\mathrm{O}$ artigo está organizado como segue: na seção 2 são apresentados estudos correlacionados à extração/inferência de personalidade; na seção 3 é descrita a metodologia; na seção 4, o experimento é introduzido; na seção 5, os resultados obtidos são apresentados, seguido, na seção 6, pelas conclusões, pelos agradecimentos e pelas referências bibliográficas.

\section{Trabalhos relacionados}

Algumas pesquisas têm sido conduzidas e direcionadas à questão de obter um método alternativo para inferir a personalidade humana, fugindo do uso de tradicionais testes de mensuração explícitos. Quercia et al. [7] apresentam em seus estudos como mensurar a personalidade de um indivíduo a partir das informações públicas de seu perfil da rede social Facebook. Informações como a quantidade de fotos do usuário, páginas curtidas e postagens realizadas/recebidas, entre outros são mineradas. Eles demostraram algumas possíveis correlações entre certas informações e os fatores do Big Five como, por exemplo, a correlação do fator extroversão com a quantidade de grupos, quantidade de amigos e de opções curtidas. Entretanto, houve casos, como o exemplo da agradabilidade, em que o valor obtido no estudo da correlação equivalente foi baixo.

Quercia et al. [8], inclusive, mostraram em outro estudo sobre como inferir a personalidade do usuário com as informações públicas do perfil desse mesmo usuário no Twitter. A inferência foi baseada na quantidade de usuários que o seguiram ou na quantidade que esseseguiu e as postagens realizadas (tweets). Algumas correlações foram encontradas. A mais relevante foi a correlação entre o fator extroversão e a quantidade de indivíduos que o usuário efetivamente seguia nessa rede social.

Tais pesquisas mostram que é possível inferir características de personalidade do usuário de uma forma menos onerosa e implícita, pois esses não passaram explicitamente pelo processo tradicional de extração via questionário/testes. Porém, esse tipo de abordagem também apresenta falhas, tais como: há casos em que o usuário não tem perfil em redes sociais e, assim, não há como inferir sua personalidade implicitamente, nesses casos ele necessita de uma forma de inferência explícita, porém menos onerosa que os testes de trezentas ou 120 questões. Portanto, como alternativa, Dennis et al. [9] apresentaram uma forma menos onerosa e explícita de inferência de personalidade, eles propuseram vinte enredos criados a partir das questões do NEO-IPIP [4]. Entretanto, Dennis et al. [9] frisaram que houve problemas em algumas medições, como no fator consciência e abertura a experiências, as quais não retornaram a correlação esperada.

As formas de extração, diferentes dos tradicionais testes apresentados, demostram que existe espaço para novos estudos e um grande potencial na busca por formas alternativas e menos onerosas para inferência de personalidade. Uma das lacunas encontradas nos trabalhos citados refere-se ao uso do Big Five, ou seja, os experimentos basearam-se apenas nos cinco fatores que diferenciam a personalidade, diferentemente do NEOIPIP que apresenta cinco fatores e seis facetas adicionais a cada fator, totalizando trinta características inferidas da personalidade humana. Assim, este artigo propõe um experimento que compara os resultados extraídos a partir de um teste de personalidade já consagrado (baseado no Big Five) intitulado NEO-IPIP e uma proposta experimental de teste baseado em histórias/enredos formulado a partir do NEO-IPIP. 


\section{Metodologia}

\subsection{Materiais}

A metodologia usada no experimento foi segmentada em duas etapas: (1) a primeira etapa consistiu em coletar a personalidade dos participantes, por meio de um teste explicito, baseado em questionários; (2) a segunda etapa consistiu em coletar os traços de personalidade desses participantes, usando o teste experimental e, também explicito, baseado em estórias.

\subsection{Procedimento}

Para inferir a personalidade de cada participante foram propostos dois diferentes testes: (1) o teste para a inferência de personalidade, baseado em questionários explícitos foi o teste NEO-IPIP 120, disponível online e com acesso público [4]; (2) o teste usado para inferência de personalidade explícita baseada em história foi o story-based Personality Inventory, proposto por este trabalho. Esse teste foi disponibilizado numa plataforma experimental para essa pesquisa e foi aberto ao público convidado (a versão textual do teste está disponível em [10], incluindo uma amostra desse no Anexo 1 deste documento).

\subsection{Participantes}

Os participantes do experimento são provenientes de uma base de dados cedida por John A. Johnson. A base contém, aproximadamente, 20 mil registros, o que equivale ao mesmo número de participantes para o experimento. A base de dados é proveniente do teste NEO-IPIP 300 (essa base é parte de um portfolio/benchmark já existente, de propriedade do criador do NEO-IPIP-John A. Johnson), assim a coleta de dados não foi explícita para o story-based e sim foi uma base cedida e adaptada por meio de cálculos nas respostas dos respondentes para que se configurasse as supostas respostas referente às questões do story-based.).

\subsection{Hipótese}

Acredita-se que há uma correlação entre os testes NEO-IPIP, baseados em questionários, e o teste baseado em histórias/enredos propostos pelos autores.

\section{Experimento}

\subsection{Etapa 1 - Teste baseado em questionário}

\subsubsection{Dataset}

O dataset foi composto pelo conjunto de respostas dos aproximadamente 20 mil participantes em relação às questões do NEO-IPIP 120 (respostas já existentes e reais provenientes da base de dados cedida).

\subsubsection{Ferramentas de inferência}

A ferramenta usada para coletar as respostas dos cerca de 20 mil participantes, via base cedida por Johnson, foi o teste NEO-IPIP 300 (disponível originalmente na página http://www.personal.psu.edu/j5j/IPIP/).

\subsubsection{Procedimento de mapeamento}

Como a base cedida por Johnson foi relacionada ao teste de trezentas questões e a base, efetivamente, usada em nosso experimento foi a base relacionada ao teste de 120 questões. Considerando que a base de 120 questões não existe formalizada, foi então necessário, criá-la. Para a criação da base de 120 foi necessário mapear as respostas do teste de trezentas questões para o teste de 120 questões. O mapeamento foi sugerido pelo próprio Johnson, considerando que o próprio teste original de 120 questões já fora criado a partir do teste de 
trezentas questões. Isto é, Johnson afirmou que todas as 120 questões do NEO-IPIP 120, efetivamente, existem no NEO-IPIP 300, bem como existe a correlação provada entre os dois questionários [5].

Por meio do mapeamento foi criada uma nova base com cerca de 20 mil registros, contendo apenas as 120 questões respondidas referentes ao NEO-IPIP 120 e originárias do NEO-IPIP 300 referente aos 20 mil participantes.

\subsection{Etapa 2 - Teste baseado em histórias}

\subsubsection{Dataset}

$\mathrm{O}$ dataset foi composto pelo conjunto de respostas dos 20 mil participantes com relação às questões do story-based, mapeadas por meio do NEO-IPIP 120 (a explicação sobre o mapeamento das questões originais para as respostas aos enredos segue abaixo).

\subsubsection{Ferramentas de inferência}

O story-based Personality Test é uma ferramenta que foi criada como uma alternativa de uso de enredos/estórias para o conjunto de 120 questões do NEO-IPIP 120. Os enredos foram criados a partir da ideia utilizada por Dennis et al. [9]. Um dos diferenciais do método de Dennis et al. é que os enredos medem também as facetas, além de apenas os cinco fatores do Big Five [10].

No teste NEO-IPIP 120, a formalização/contabilização da personalidade é feita por meio de um conjunto de cálculos (cedidos por Johnson). Cada uma das 120 questões têm um caráter positivo ou negativo que está diretamente relacionadas às suas facetas. Nos enredos criados, as questões foram agrupadas por facetas e por caráter positivo ou negativo. Foram gerados 51 enredos a partir das 120 questões originais do NEO-IPIP 120. Cada faceta tem quatro questões no teste NEO-IPIP 120. Para ilustrar, na Tabela 1, apresenta-se o exemplo: (1) da faceta "ansiedade" com as quatro questões positivas e um enredo criado. (Note que o enredo é basicamente similar às questões existentes, que nesse caso eram quatro, entretanto criadas agora na forma de narrativa o que representa o enredo).

Tabela 1: Exemplo de grupos de questões e enredo correspondentes

\begin{tabular}{llll}
\hline & Faceta & Questões & Enredo criado \\
\hline 1 & Ansiedade & Me preocupo com as coisas. & Miguel é uma pessoa que se preocupa no \\
& & Temo o pior. Tenho medo de & geral, tem medo de muitas coisas. Ele se \\
& muitas coisas. Me estresso & estressa com facilidade e teme o pior. \\
& & &
\end{tabular}

Fonte: autoria própria (2014).

\subsubsection{Procedimento de mapeamento}

Para mapear as questões do NEO-IPIP 120, após terem sido agrupadas pela faceta que às mensuravam, tal grupo foi subdividido em dois: os que continham as questões de caráter positivo e as de caráter negativo. A quantidade de questões agrupadas em cada subgrupo para a transformação em enredo foi armazenada como o "peso" do enredo criado. O peso foi utilizado no cálculo para mensurar a faceta correspondente do enredo (não aprofundado no artigo devido às questões de propriedade intelectual do autor do teste Dr. John A. Johnson).

\section{Resultados obtidos}

Os resultados de cada teste foram submetidos a uma diferença de distância absoluta, o que significa que foi calculado o valor absoluto da diferença entre o resultado de cada faceta, ofator do NEO-IPIP 120 e o storybased, no qual foi aplicada a correlação de Pearson. O NEO-IPIP 120 classifica o indivíduo em três categorias com relação aos fatores, e facetas com relação à pontuação obtida no teste: baixo (até 45 pontos), médio (entre 45 e 55 pontos) e alto (acima de 55 pontos). Distâncias entre pontuações maiores que vinte foram consideradas péssimas, pois um usuário facilmente de uma categoria seria encaixado em outra, entre vinte e dez foram 
consideradas ruins, ainda considerando o mesmo problema, distâncias entre dez e cinco foram consideradas aceitáveis, já que apenas uma pontuação próxima do limiar de uma categoria poderia ser encaixada em outra, entre cinco e dois consideradas boas pelo fato de ambas pontuações precisarem estar muito próximas do limiar de duas categorias, e as menores que dois consideradas excelentes, por praticamente não permitir que um usuário de uma categoria fosse inserido em outra. As Figuras de 1 a 5 apresentam as diferenças para cada faceta e fator e, a Figura 6, o gráfico da correlação de Pearson.

Figura 1: Resultados sobre o fator abertura a experiências e suas facetas

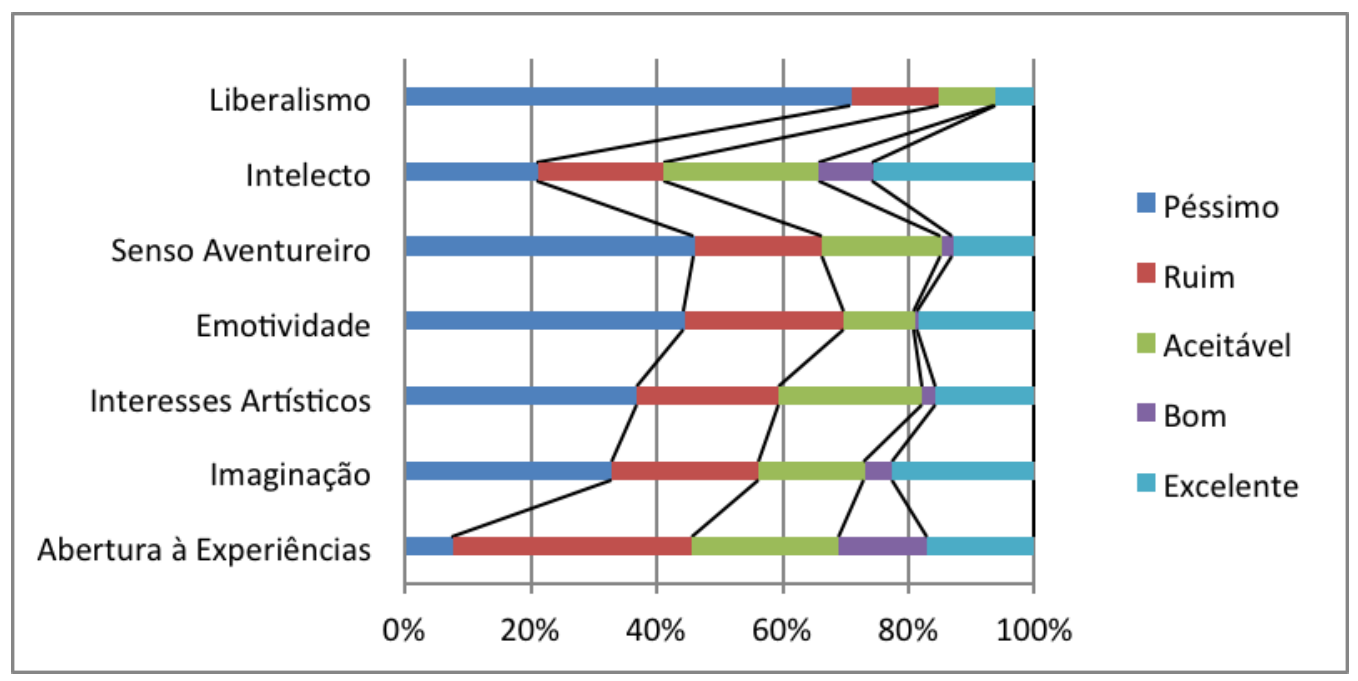

Fonte: autoria própria (2014).

Figura 2: Resultados do fator consciência e suas facetas

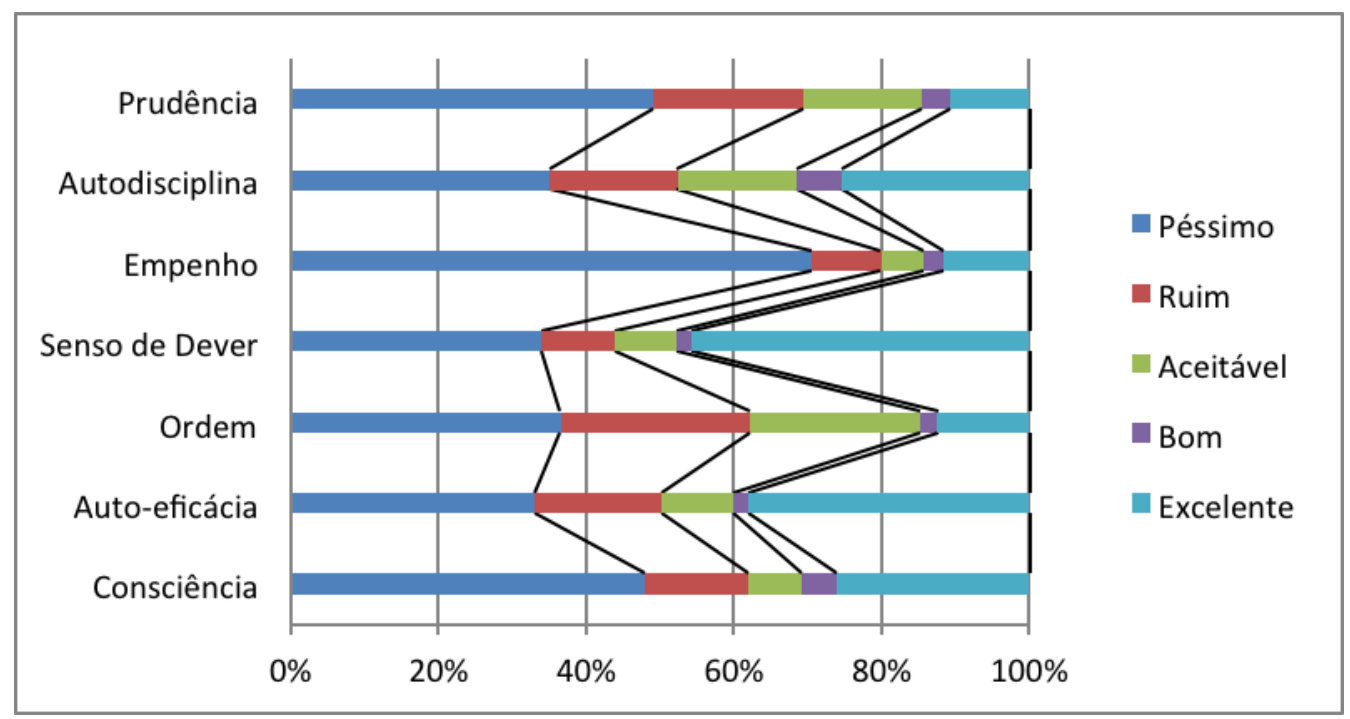

Fonte: autoria própria (2014). 
Figura 3: Resultados do fator extroversão e suas facetas

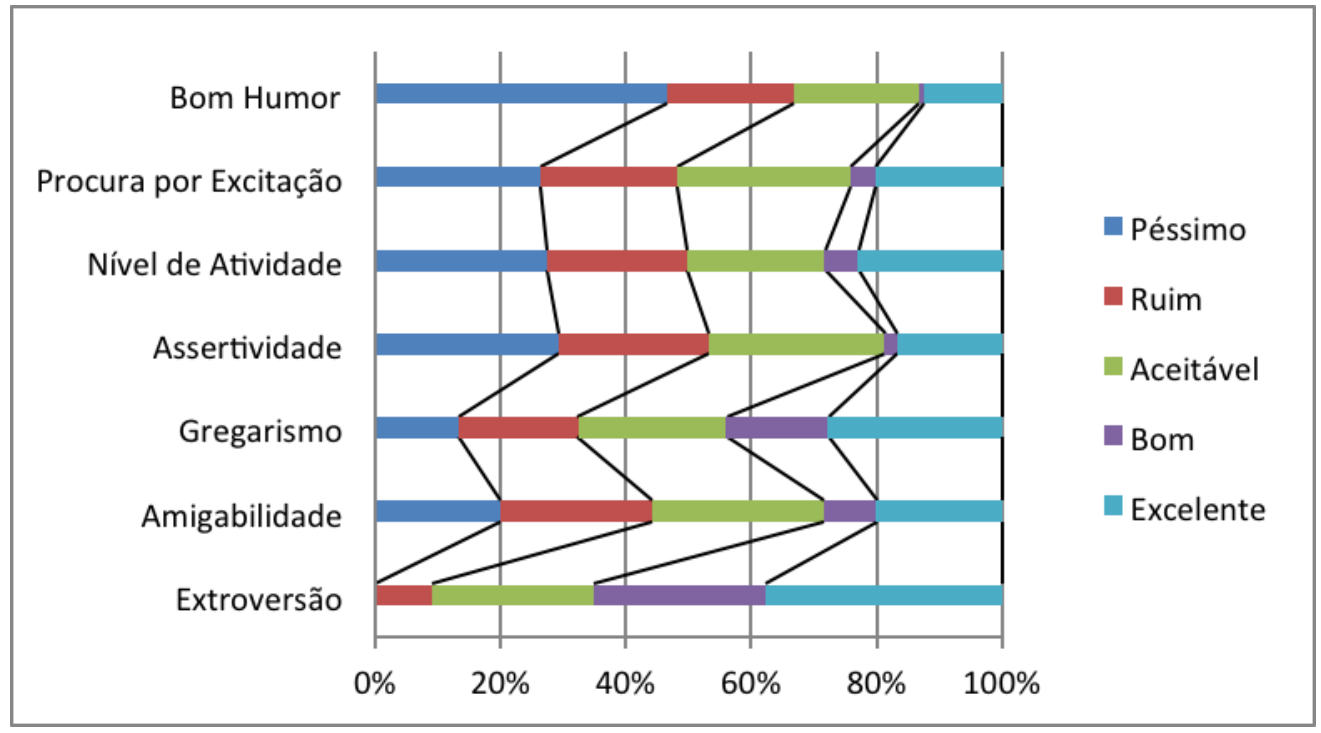

Fonte: autoria própria (2014).

Figura 4: Resultados sobre o fator Agradabilidade e suas facetas

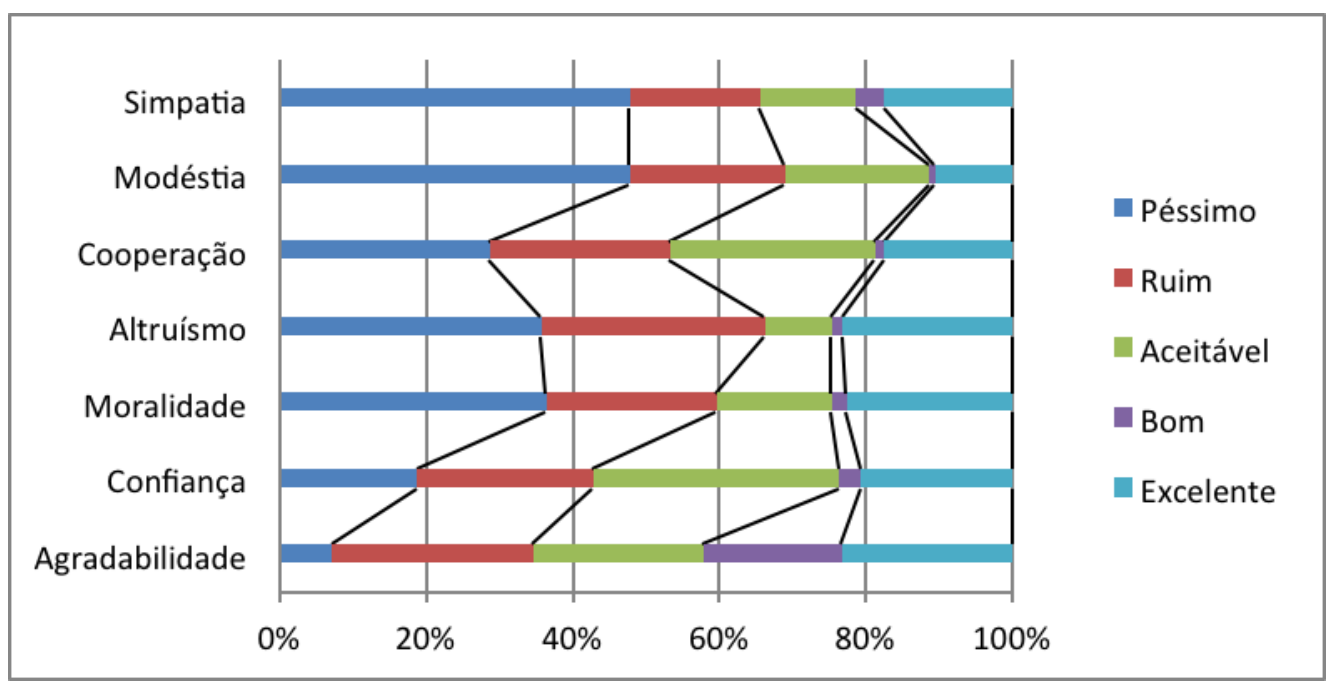

Fonte: autoria própria (2014). 
Figura 5: Resultados sobre o fator neuroticismo e suas facetas

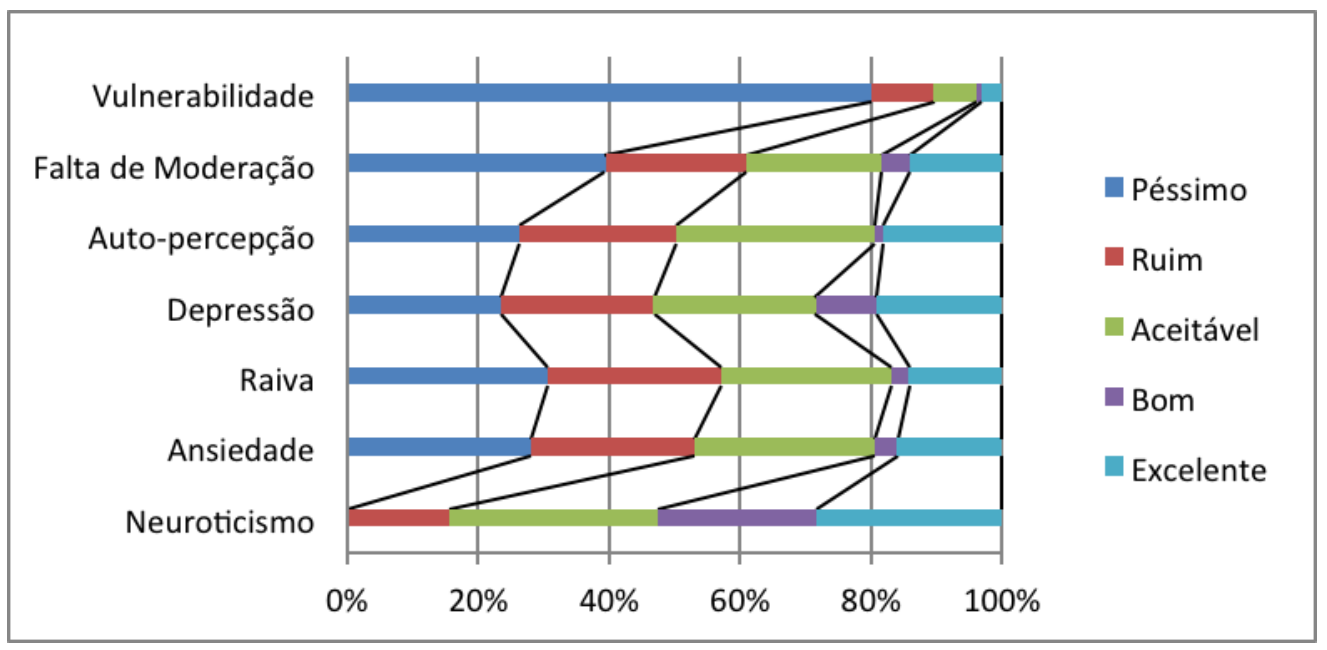

Fonte: autoria própria (2014).

Figura 6: Correlação de Pearson para os resultados

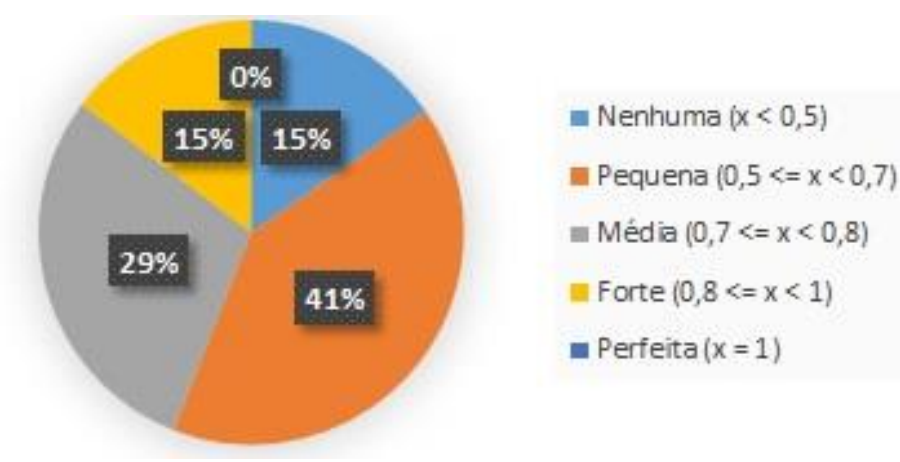

Fonte: autoria própria (2014).

\subsection{Análise dos resultados}

A quantidade de distâncias consideradas perfeitas encontradas nos fatores abertura a experiências, agradabilidade e neuroticismo (inclusive nas facetas de cada um), foram muito baixas (uma média de aproximadamente 20\%). Uma grande quantidade de distâncias considerada altas impossibilita afirmar uma correlação entre os resultados de ambos os testes. As distâncias do fator consciência foram as melhores encontradas, pois uma média de $22 \%$ foi considerada excelente nos resultados, mas apenas as facetas senso de dever e autoeEficácia retornaram com um resultado interessante (e inclusive a maior quantidade de uma distância excelente de todos os resultados, aproximadamente 40\%). A respeito do fator extroversão, as distâncias excelentes de suas facetas foram em torno de $20 \%$, mas o fator retornou quase $40 \%$ de distâncias excelentes. Infelizmente, com esses valores e essa amostra acredita-se que não é confiável utilizar o método story-based para uma extração efetiva, mesmo que parcial da personalidade. Esse experimento demostrou que se deve optar por uma base de dados efetivamente específica, baseada em respostas isoladas do NEO-IPIP e story-based. Dessa forma, novos experimentos serão realizados, objetivando validar nossa hipótese inicial. 


\section{Conclusões e trabalhos futuros}

Este trabalho apresentou um relato de um experimento inicial que buscou encontrar correlações entre os resultados das ferramentas de extração de personalidade baseada em teste e em enredos/estórias (story-based). Não houve uma comprovação da hipótese nesse experimento com a amostra proposta. O principal fator que contribuiu para o resultado negativo desse experimento foi a amostra mapeada (como apresentada anteriormente). Considerando a baixa quantidade de voluntários, fez-se a tentativa de utilizar uma base de dados já existente, validada e consistente do NEO-IPIP 300 (cedida por Johnson); realizou-se o mapeamento para as questões do NEO-IPIP 120; e, finalmente, um novo mapeamento para usar como dados de entrada ao método story-based. Justamente pelo fato de não terem sido efetivamente respostas voluntárias usadas no story-based (como já descrito, pois as respostas foram criadas a partir de cálculos baseados na resposta original do NEO-IPIP 120 que fora extraído do NEO-IPIP 300, segundo sugestão de Johnson), as informações mapeadas podem ter distorcido as supostas reais respostas dos respondentes originais (se eles efetivamente tivessem a oportunidade de ter respondido ao teste story-based). Confiante no story-based e na necessidade crescente de alternativas de extração/inferência de personalidade, como descrito nos trabalhos relacionados, como trabalho futuro esse experimento será aplicado a uma amostra alternativa sem uso de mapeamento de informações. Realizada tais adaptações procedimentais, acredita-se que é possível que as correlações sejam maiores e a hipótese seja comprovada.

\section{Agradecimentos}

À Universidade Federal de Sergipe pelo apoio. Ao CNPq, pela bolsa de Iniciação Tecnológica (IT) e bolsa de Produtividade em Desenvolvimento Tecnológico (DT). À John A. Johnson, por ter cedido a base de dados para a realização dos testes. À Malu Matos, pela realização dos cálculos das correlações.

\section{Referências}

[1] NUNES, M. A. S. N. Recommender systems based on personality traits: could human psychological aspects influence the computer decision-making process? VDM Verlag. Müller, BE. 2009.

[2] JOHN, O. P. AND SRIVASTAVA, S. The big five trait taxonomy: History, measurement, and theoretical perspectives. In: Handbook of Personality: Theory and Research, L. A. PERVIN AND O. P. JOHN (Eds.). Guilford Press, New York, NY, 1999 p. 102-138.

[3] JOHNSON, J.A. Predicting observers ratings of the big five from the cpi, hpi, and neo-pi-r: A comparative validity study. European Journal of Personality, v. 14, n. 1, p. 1-19. 2000.

[4] INTERNATIONAL PERSONALITY ITEM POOL. International Personality Item Pool: A Scientific Collaboratory for the Development of Advanced Measures of Personality and Other Individual Differences. Retrieved July 3, 2013.

[5] JOHNSON, J. A. 2001. Screening Massively Large Data Sets For Non-Responsiveness In Web-Based Personality Inventories.

[6] NUNES, M. A. S. N.; CAZELLA, S. C. O que sua personalidade revela? Fidelizando clientes web através de sistemas de recomendação e traços de personalidade. In: Tópicos em Banco de Dados e Multimídia e Web. $\mathrm{P}$ VILAIN AND V. ROESLER (Orgs.). SBC, Porto Alegre, 2011. p. 91-122.

[7] QUERCIA, D.; LAMBIOTTE, R.; STILLWELL, D.; KOSINSKI, M. ;CROWCROFT, J. Personality of popular facebook. In: Proceedings of the ACM 2012 conference on computer supported cooperative work, ACM CSCW 2012, Seattle, Washington, February 2012, ACM, New York, NY, 2012, p. 955-964. 
[8] QUERCIA, D.; KOSINSKI, M.; STILLWELL, D. AND CROWCROFT, J. Our Twitter Profiles, Our Selves: Predicting Personality with Twitter. In: IEEE International Conference on Social Computing, SocialCom, Boston, Massachusetts, October 2011, Piscataway, New Jersey, 2011. p. 180-185.

[9] DENNIS, M.; MASTHOFF, J.; MELLISH, C. The quest for validated personality trait stories. In: Proceedings of the 2012 ACM international conference on Intelligent User Interfaces, IUI '12. ACM, New York, NY, USA. 2012. p. 273-276.

[10] NUNES, M. A. S. N. ; CARDOSO, G. G. ; SANTANA, M. S. ; SANTOS, D. G. ; MATOS, M. L. S. ; COSTA, M. S. N. 2013. Teste de personalidade Story-based para a inferência de personalidade humana via enredos. São Cristóvão: Editora UFS. 
Anexo 1: Exemplo de uma estória extraída do teste de personalidade baseado em estórias

\section{ANSIEDADE}

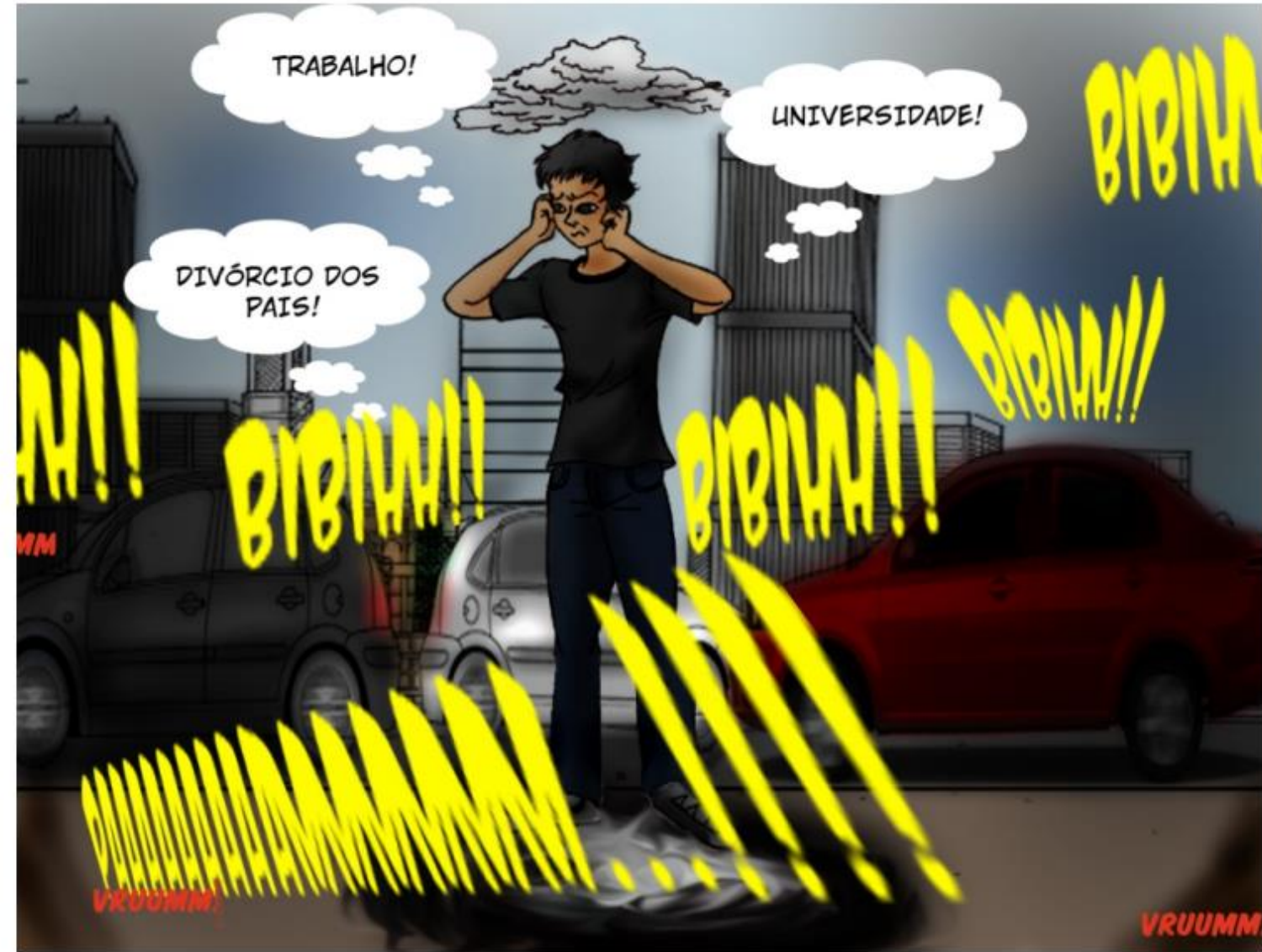

Miguel é uma pessoa que se preocupa no geral, tem medo de muitas coisas. Ele se estressa com facilidade e teme o pior. 